\title{
Metals Are Integral to Life as We Know It
}

\author{
Daniele Rossetto ${ }^{1}$ and Sheref S. Mansy ${ }^{1,2 *}$ \\ ${ }^{1} D$-CIBIO, University of Trento, Povo, Italy, ${ }^{2}$ Department of Chemistry, University of Alberta, Edmonton, AB, Canada
}

Investigations of biology and the origins of life regularly focus on the components of the central dogma and thus the elements that compose nucleic acids and peptides. Less attention is given to the inorganic components of a biological cell, which are required for biological polymers to function. The Earth was and continues to be rich in metals, and so investigations of the emergence and evolution of life must account for the role that metal ions play. Evolution is shaped by what is present, and not all elements of the periodic table are equally accessible. The presence of metals, the solubility of their ions, and their intrinsic reactivity all impacted the composition of the cells that emerged. Geological and bioinformatic analyses clearly show that the suite of accessible metal ions changed over the history of the Earth; however, such analyses tend to be interpreted in comparison to average oceanic conditions, which do not represent well the many niche environments present on the Earth. While there is still debate concerning the

OPEN ACCESS

Edited by:

Simone Ciofi Baffoni,

University of Florence, Italy

Reviewed by:

Terence Phillip Kee,

University of Leeds, United Kingdom Michael Assfalg,

University of Verona, Italy

*Correspondence:

Sheref S. Mansy

sheref.mansy@ualberta.ca

Specialty section:

This article was submitted to

Cellular Biochemistry,

a section of the journal

Frontiers in Cell and Developmental

Biology

Received: 28 January 2022

Accepted: 18 February 2022

Published: 04 March 2022

Citation:

Rossetto D and Mansy SS (2022)

Metals Are Integral to Life as We

Know It.

Front. Cell Dev. Biol. 10:864830.

doi: 10.3389/fcell.2022.864830 sequence of events that led to extant biology, what is clear is that life as we know it requires metals, and that past and current metal-dependent events remain, at least partially, imprinted in the chemistry of the cell.

Keywords: origins of life, prebiotic chemistry, metal ions, bioinorganic chemistry, metallopeptides

The elements necessary for extant biology are frequently referred to as CHNOPS for carbon, hydrogen, nitrogen, oxygen, phosphorous, and sulfur. While undoubtedly necessary for the synthesis of biological molecules, such as nucleic acids, proteins, and lipids, CHNOPS alone is incapable of supporting life as we know it (Figure 1). Nothing alive today or in the past on this planet can be adequately understood without invoking metals. In extant biology, metal ions aid the folding of biological polymers, catalyze the reactions of metabolism, form gradients across membranes that serve as energy reserves, and mediate signal transduction events. Every class of molecules in biology, from nucleic acids to proteins and antibiotics are impacted by metal ions, which is why living cells put so much effort in regulating the concentrations of intracellular free metal ions (Capdevila et al., 2017). What perhaps goes less frequently noticed is the impact of the environment on the distribution and exploitation of metal ions in biology. We are accustomed to viewing biology in the light of evolution and how environmental conditions shape emergent phenotypes. The role of metal ions in biology is no different. Our planet has always been rich in metals, so Darwinian evolution must be thought of in the context of these conditions. Metal ions affect ionic polymers, such as nucleic acids and the soluble domains of proteins, by neutralizing charges and thus facilitating the formation of the tertiary folds necessary for activity. Further, metals themselves intrinsically possess catalytic activity. Since it is easier to scavenge existing parts (i.e. metal ions) for needed function rather than to build from scratch, it is not surprising that metal ions are frequently found within the active sites of enzymes. We see this in both biology and in vitro evolution experiments (Bartel and Szostak, 1993; Monreal Santiago et al., 2020), where selected polymers frequently rely on the activity of a coordinated metal ion, even if metal-dependent function was not 


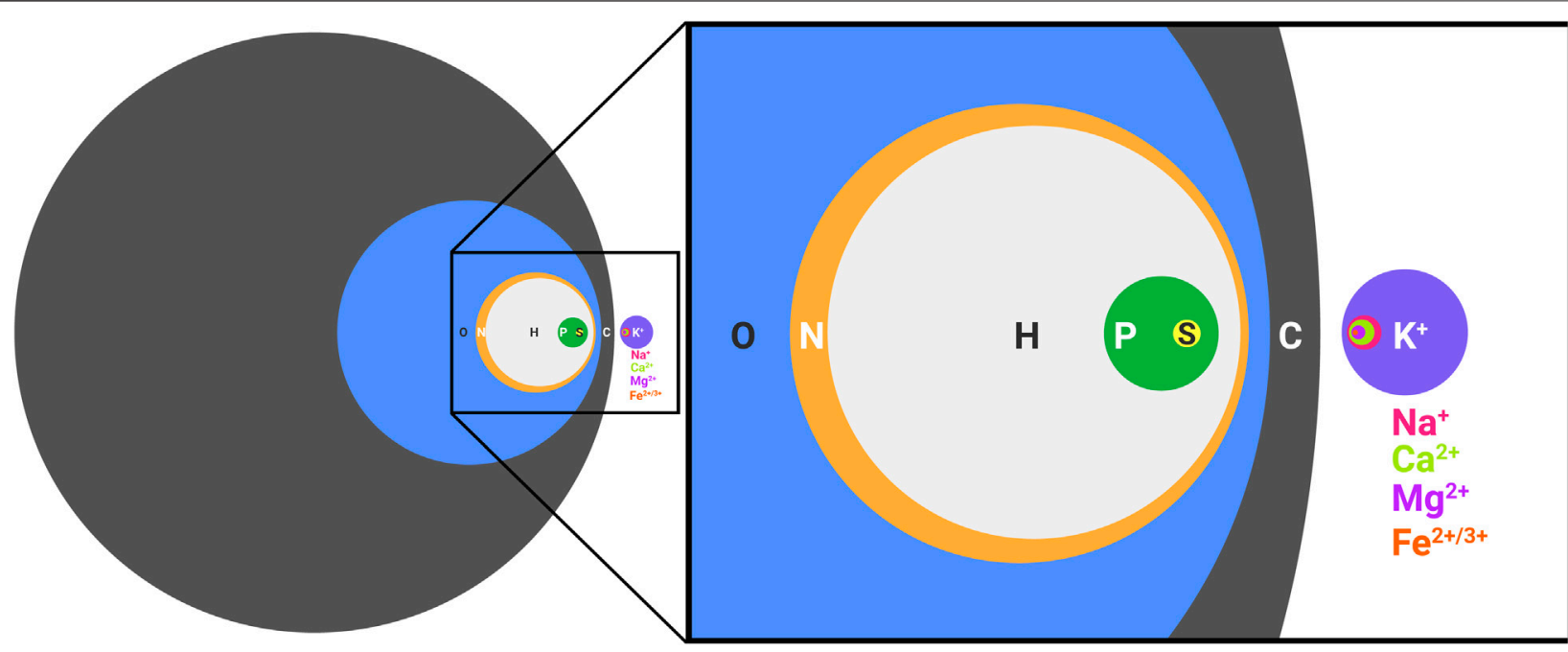

FIGURE 1 | CHNOPS and the most abundant metal ions of a biological cell. Diameters are proportional to percent dry weight. Data are of an average bacterial composition and taken from Lawford and Rousseau, 1996; Tchobanoglous Burton, Franklin L., Stensel, H. David, Metcalf and Eddy, 2003.

intentionally sought (Seelig and Szostak, 2007). We know that in many instances metal-independent activity is possible, because the natural metal-dependent activity of some enzymes can be used as a starting point to engineer metal-independent activity (Casareno et al., 1995), and when environments change, metal reliant pathways can evolve to exploit the use of organic cofactors in place of metal ions (Daniel and Danson, 1995). However, metal-dependent catalysis does not require the formation of a stable complex. Instead, metal ions can enter and exit an active site, as needed, to mediate turnover. Such a scenario is observed for Bacillus halodurans $\mathrm{RNase} \mathrm{H}$, which exploits for catalysis a transient $\mathrm{Mg}^{2+}$ and two transient $\mathrm{K}^{+}$that do not make direct contact with the protein (Samara and Yang, 2018). Such dynamics are possible because the intracellular concentrations of $\mathrm{Mg}^{2+}$ and $\mathrm{K}^{+}$are high, so high affinity, static binding is not necessary.

If biology exploits what is accessible, then it is reasonable to ask which metal ions were present. Relative abundancies throughout the universe roughly correlate with atomic number, with smaller elements of even atomic number found in greater abundance than larger elements of odd atomic number (Da Silva and Williams, 2001). However, planetary compositions, unsurprisingly, are different from each other due to the impact of gravity and heat from the sun, leading to smaller, metal-rich planets closer to the sun, such as the Earth, and larger, more gaseous planets with lower metal abundancies further away. Further deviations result from meteoritic impacts. The metals of greatest abundance on the Earth are the alkali and alkaline Earth metals of periods two to four and the first-row transition metals. Trivalent and higher valent metal cations are not typically encountered, because of their precipitation as hydroxides and oxides. Therefore, solubility limits the accessible options to mono- and di-valent cations. A clear example of this is the change in concentration of oceanic iron before $\left(\sim 10^{-7} \mathrm{mM}\right.$ $\left.\mathrm{Fe}^{2+}\right)$ and after $\left(\sim 10^{-19} \mathrm{mM} \mathrm{Fe}{ }^{3+}\right)$ the great oxidation event. The appearance of oxygen also altered the ratios of sulfate to sulfide, which in turn affected the solubility of metal ions. Metal sulfates are highly soluble in comparison to metal sulfides, and so the concentrations of some metal ions, such those of copper and zinc, increased after the Earth became aerobic. In fact, copper and zinc-dependent enzymes are found much more frequently in higher organisms that emerged after the great oxidation event. While loss of a specific metal ion could be detrimental, that was likely not always the case. Some enzymes retain function with different metal ions. For example, some forms of superoxide dismutase (SOD) are functional as $\mathrm{Fe}^{2+}$ - or $\mathrm{Mn}^{2+}$-bound protein (Meier et al., 1982). Similar promiscuity was likely common in the past, particularly with $\mathrm{Fe}^{2+}$, which could have been used in place of $\mathrm{Mg}^{2+}$ (Moore et al., 2017; Okafor et al., 2017). The common binding motifs between iron-sulfur clusters and $\mathrm{Zn}^{2+}$ also suggest that more ancient scaffolds may have been used for the coordination of newly available metal ions (Belmonte and Mansy, 2017; Shimberg et al., 2018). Although oceanic concentrations of metal ions fluctuated over the history of the Earth, some metal ions, such as $\mathrm{Na}^{+}, \mathrm{K}^{+}, \mathrm{Mg}^{2+}$, and $\mathrm{Ca}^{2+}$, are soluble as sulfides and oxides, and thus may not have changed much.

While it is instructive to assess the compositional evolution of the ocean, oceanic conditions are not where all life evolved. The planet is highly varied in composition and conditions, and so care must be taken when inferring past events based on average conditions of the ocean. For example, despite the much lower abundance of molybdenum ( 100-fold lower concentration) in the sea of the anaerobic Earth in comparison to iron, evolutionary analysis indicates that Mo-dependent nitrogenase predates $\mathrm{Fe}$ dependent nitrogenase (Kacar et al., 2021). This suggests that such enzymes emerged from organisms in niche environments not well represented by average oceanic conditions. The same is likely true for the emergence of the Earth's first cells, which likely did not occur under the average conditions of the Earth. Several competing theories exist, with prebiotic chemistry of surface lake conditions being the most intensely investigated (Sasselov et al., 
2020). Lake conditions are attractive since lakes can harness the energy of the sun and can keep molecules necessary for life, such as phosphate, soluble. Lakes rich in carbonate would have led to the precipitation of complexes with $\mathrm{Mg}^{2+}$ and $\mathrm{Ca}^{2+}$, thus decreasing the concentrations of these metal ions, which would have facilitated the formation of protocellular structures (Toparlak et al., 2020) and allowed for phosphate concentrations higher than one molal (Toner and Catling, 2020). While decreasing the concentration of $\mathrm{Mg}^{2+}$ may have been helpful for some chemical steps, $\mathrm{Mg}^{2+}$ would have facilitated other necessary reactions. $\mathrm{Mg}^{2+}$-binding sites are postulated to be older than the last universal common ancestor (LUCA), and at least $18 \%$ of extant gene products are thought to bind $\mathrm{Mg}^{2+}$ (Shalaeva et al., 2018).

Since the enzymes that mediate metabolism are heavily reliant on metal cofactors, many suspect that prebiotic analogues of extant metabolism may have operated on the prebiotic Earth in a metal-dependent fashion. The degree of involvement of metal ions is debated, with some advocating for a strong role in catalyzing glycolysis (Keller et al., 2014) and the citric acid cycle (Muchowska et al., 2019), and others advocating for a diminished role (Stubbs et al., 2020). Nevertheless, metal ions must have impacted prebiotic chemistry, as it is difficult to imagine environments completely devoid of metals. Copper (Patel et al., 2015) and iron (Xu et al., 2018) ions have been invoked in cyanosulfidic protometabolic pathways that synthesize RNA, amino acids, and lipid precursors. The prebiotic synthesis of phosphoenol pyruvate exploits manganese (Coggins and Powner, 2017), and the non-enzymatic copying and ligation of RNA strands relies on $\mathrm{Mg}^{2+}$ (Adamala and Szostak, 2013). More complex metallocofactors, such as iron-sulfur clusters, can be synthesized prebiotically (Bonfio et al., 2017), retain redox activity when bound to small peptides (Scintilla et al., 2016; Kim et al., 2018), and can engage in electron transfer reactions that generate a proton gradient across a lipid membrane (Bonfio et al., 2018).

Billions of years of evolution have given rise to organisms that are supported by finely tuned chemistry, which can be seen by how metals are used in biology. Signal transduction makes use of metal ions with fast ligand exchange rates, such as $\mathrm{Na}^{+}, \mathrm{K}^{+}$, and

\section{REFERENCES}

Adamala, K., and Szostak, J. W. (2013). Nonenzymatic Template-Directed RNA Synthesis inside Model Protocells. Science 342, 1098-1100. doi:10.1126/science. 1241888

Barge, L. M., Rodriguez, L. E., Weber, J. M., and Theiling, B. P. (2021). Determining the "Biosignature Threshold" for Life Detection on Biotic, Abiotic, or Prebiotic Worlds. Astrobiology [Epub ahead of print]. doi:10.1089/ast.2021.0079

Bartel, D., and Szostak, J. (1993). Isolation of New Ribozymes from a Large Pool of Random Sequences [see Comment]. Science 261, 1411-1418. doi:10.1126/ science.7690155

Belmonte, L., and Mansy, S. S. (2017). Patterns of Ligands Coordinated to Metallocofactors Extracted from the Protein Data Bank. J. Chem. Inf. Model. 57, 3162-3171. doi:10.1021/acs.jcim.7b00468

Bonfio, C., Godino, E., Corsini, M., Fabrizi de Biani, F., Guella, G., and Mansy, S. S. (2018). Prebiotic Iron-Sulfur Peptide Catalysts Generate a $\mathrm{pH}$ Gradient across Model Membranes of Late Protocells. Nat. Catal. 1, 616-623. doi:10.1038/s41929-018-0116-3
$\mathrm{Ca}^{2+}$ (Cowan, 1997). Enzymes exploit the Lewis acidity of metal ions, e.g. $\mathrm{Zn}^{2+}$, to mediate reactions with small substrates that would be difficult to achieve with only protein sidechains (Da Silva and Williams, 2001). However, the origins of the observed metal dependencies reflect what is or was readily accessible. An instructive example of how metal dependence can become embedded is seen by the lengths that modern organisms, including pathogenic bacteria (Capdevila et al., 2017), go to acquire $\mathrm{Fe}^{2+}$. Ultimately, life relies on a conserved set of metal ions in a way that is not too dissimilar from the well-recognized dependencies on a shared genetic code and a common central metabolism. What is less clear is the extent that each of these central pillars of biology rely on each other, and similarly, if life must be constructed from these same parts. It is easy to propose that different planetary conditions could give rise to life completely orthogonal to ours today, but it is more difficult to imagine when considering the limits of availability and accessible chemistry (Pace, 2001). To date, few have attempted to define the metal requirements for the emergence of life (Zerkle et al., 2005; McKay, 2014; Barge et al., 2021). Although evolution suggests that there is unlikely to be a requirement for one specific metal, the probability of prebiotic chemistry advancing towards cell-like activity may be significantly lower in the absence of the intrinsic catalytic activity of metal ions in general. As the search for extraterrestrial life focuses on rocky planets, there is already a presumption to the importance of metals. The variable, instead, is accessibility.

\section{AUTHOR CONTRIBUTIONS}

Both authors wrote the manuscript together.

\section{FUNDING}

We thank the Simons Foundation (290358FY18 and 290358FY19) and the Natural Sciences and Engineering Research Council of Canada (NSERC) (RGPIN-2020-04375) for funding.

Bonfio, C., Valer, L., Scintilla, S., Shah, S., Evans, D. J., Jin, L., et al. (2017). UVlight-driven Prebiotic Synthesis of Iron-Sulfur Clusters. Nat. Chem 9, 1229-1234. doi:10.1038/nchem.2817

Capdevila, D. A., Edmonds, K. A., and Giedroc, D. P. (2017). Metallochaperones and Metalloregulation in Bacteria. Essays Biochem. 61, 177-200. doi:10.1042/ EBC20160076

Casareno, R., Li, D., and Cowan, J. A. (1995). Rational Redesign of a Metal-dependent Nuclease. Engineering the Active Site of Magnesium-dependent Ribonuclease $\mathrm{H}$ to Form an Active "Metalindependent" Enzyme. J. Am. Chem. Soc. 117, 11011-11012. doi:10. 1021/ja00149a026

Coggins, A. J., and Powner, M. W. (2017). Prebiotic Synthesis of Phosphoenol Pyruvate by a-phosphorylation-controlled Triose Glycolysis. Nat. Chem 9, 310-317. doi:10.1038/nchem.2624

Cowan, J. A. (1997). Inorganic Biochemistry: An Introduction. Wiley.

Da Silva, F. J. J. R., and Williams, R. J. P. (2001). The Biological Chemistry of the Elements : The Inorganic Chemistry of Life. 2nd ed. Oxford; New York: Oxford University Press. 
Daniel, R. M., and Danson, M. J. (1995). Did Primitive Microorganisms Use Nonhem Iron Proteins in Place of NAD/P? J. Mol. Evol. 40, 559-563. doi:10. 1007/BF00160501

Kacar, B., Garcia, A. K., and Anbar, A. D. (2021). Evolutionary History of Bioessential Elements Can Guide the Search for Life in the Universe. ChemBioChem 22, 114-119. doi:10.1002/cbic.202000500

Keller, M. A., Turchyn, A. V., and Ralser, M. (2014). Non-enzymatic Glycolysis and Pentose Phosphate Pathway-like Reactions in a Plausible Archean Ocean. Mol. Syst. Biol. 10, 725. doi:10.1002/msb.20145228

Kim, J. D., Pike, D. H., Tyryshkin, A. M., Swapna, G. V. T., Raanan, H., Montelione, G. T., et al. (2018). Minimal Heterochiral De Novo Designed 4Fe-4S Binding Peptide Capable of Robust Electron Transfer. J. Am. Chem. Soc. 140, 11210-11213. doi:10.1021/jacs.8b07553

McKay, C. P. (2014). Requirements and Limits for Life in the Context of Exoplanets. Proc. Natl. Acad. Sci. 111, 12628-12633. doi:10.1073/pnas.1304212111

Meier, B., Barra, D., Bossa, F., Calabrese, L., and Rotilio, G. (1982). Synthesis of Either Fe- or Mn-Superoxide Dismutase with an Apparently Identical Protein Moiety by an Anaerobic Bacterium Dependent on the Metal Supplied. J. Biol. Chem. 257, 13977-13980. doi:10.1016/s0021-9258(19)45329-5

Monreal Santiago, G., Liu, K., Browne, W. R., and Otto, S. (2020). Emergence of Light-Driven Protometabolism on Recruitment of a Photocatalytic Cofactor by a Self-Replicator. Nat. Chem. 12, 603-607. doi:10.1038/s41557-020-0494-4

Moore, E. K., Jelen, B. I., Giovannelli, D., Raanan, H., and Falkowski, P. G. (2017). Metal Availability and the Expanding Network of Microbial Metabolisms in the Archaean Eon. Nat. Geosci. 10, 629-636. doi:10.1038/ngeo3006

Muchowska, K. B., Varma, S. J., and Moran, J. (2019). Synthesis and Breakdown of Universal Metabolic Precursors Promoted by Iron. Nature 569, 104-107. doi:10.1038/s41586-019-1151-1

Okafor, C. D., Lanier, K. A., Petrov, A. S., Athavale, S. S., Bowman, J. C., Hud, N. V., et al. (2017). Iron Mediates Catalysis of Nucleic Acid Processing Enzymes: Support for Fe(II) as a Cofactor Before the Great Oxidation Event. Nucleic Acids Res. 45, 3634-3642. doi:10.1093/nar/gkx171

Pace, N. R. (2001). The Universal Nature of Biochemistry. Proc. Natl. Acad. Sci. 98, 805-808. doi:10.1097/00000441-196304000-0001410.1073/pnas.98.3.805

Patel, B. H., Percivalle, C., Ritson, D. J. D., and Duffy, J. D. (2015). Common Origins of RNA, Protein and Lipid Precursors in a Cyanosulfidic Protometabolism. Nat. Chem 7, 301-307. doi:10.1038/nchem.2202

Samara, N. L., and Yang, W. (2018). Cation Trafficking Propels RNA Hydrolysis. Nat. Struct. Mol. Biol. 25, 715-721. doi:10.1038/s41594-018-0099-4

Sasselov, D. D., Grotzinger, J. P., and Sutherland, J. D. (2020). The Origin of Life as a Planetary Phenomenon. Sci. Adv. 6, 1-9. doi:10.1126/sciadv.aax3419

Scintilla, S., Bonfio, C., Belmonte, L., Forlin, M., Rossetto, D., Li, J., et al. (2016). Duplications of an Iron-sulphur Tripeptide Leads to the Formation of a Protoferredoxin. Chem. Commun. 52, 13456-13459. doi:10.1039/c6cc07912a
Seelig, B., and Szostak, J. W. (2007). Selection and Evolution of Enzymes from a Partially Randomized Non-catalytic Scaffold. Nature 448, 828-831. doi:10. 1038/nature06032

Shalaeva, D. N., Cherepanov, D. A., Galperin, M. Y., Golovin, A. V., and Mulkidjanian, A. Y. (2018). Evolution of Cation Binding in the Active Sites of P-Loop Nucleoside Triphosphatases in Relation to the Basic Catalytic Mechanism. Elife 7, 1-35. doi:10.7554/eLife.37373

Shimberg, G. D., Pritts, J. D., and Michel, S. L. J. (2018). Iron-Sulfur Clusters in Zinc Finger Proteins. 1st ed. Elsevier, 101-137. doi:10.1016/bs.mie.2017.09.005IronSulfur Clusters in Zinc Finger Proteins

Stubbs, R. T., Yadav, M., Krishnamurthy, R., and Springsteen, G. (2020). A Plausible Metal-free Ancestral Analogue of the Krebs Cycle Composed Entirely of a-ketoacids. Nat. Chem. 12, 1016-1022. doi:10.1038/s41557-02000560-7

Toner, J. D., and Catling, D. C. (2020). A Carbonate-Rich lake Solution to the Phosphate Problem of the Origin of Life. Proc. Natl. Acad. Sci. USA 117, 883-888. doi:10.1073/pnas.1916109117

Toparlak, Ö. D., Karki, M., Egas Ortuno, V., Krishnamurthy, R., and Mansy, S. S. (2020). Cyclophospholipids Increase Protocellular Stability to Metal Ions. Small 16, 1903381-1903388. doi:10.1002/smll.201903381

Xu, J., Ritson, D. J., Ranjan, S., Todd, Z. R., Sasselov, D. D., and Sutherland, J. D. (2018). Photochemical Reductive Homologation of Hydrogen Cyanide Using Sulfite and Ferrocyanide. Chem. Commun. 54, 5566-5569. doi:10.1039/ c8cc01499j

Zerkle, A. L., House, C. H., and Brantley, S. L. (2005). Biogeochemical Signatures through Time as Inferred from Whole Microbial Genomes. Am. J. Sci. 305, 467-502. doi:10.2475/ajs.305.6-8.467

Conflict of Interest: The authors declare that the research was conducted in the absence of any commercial or financial relationships that could be construed as a potential conflict of interest.

Publisher's Note: All claims expressed in this article are solely those of the authors and do not necessarily represent those of their affiliated organizations, or those of the publisher, the editors and the reviewers. Any product that may be evaluated in this article, or claim that may be made by its manufacturer, is not guaranteed or endorsed by the publisher.

Copyright (c) 2022 Rossetto and Mansy. This is an open-access article distributed under the terms of the Creative Commons Attribution License (CC BY). The use, distribution or reproduction in other forums is permitted, provided the original author(s) and the copyright owner(s) are credited and that the original publication in this journal is cited, in accordance with accepted academic practice. No use, distribution or reproduction is permitted which does not comply with these terms. 